\title{
Os difusos processos culturais na transmodernidade em relação aos Direitos Humanos ${ }^{1}$
}

\section{Los difusos procesos culturales en la transmodernidad en relación com los Derechos Humanos}

\author{
The diffused cultural processes in transmodernity in relations to Human \\ Rights
}

Ma. Gabrieli de Camargo ${ }^{2}$

Ma. Bruna Medeiros Bolzani ${ }^{3}$

\begin{abstract}
Resumo
A pesquisa tem como proposta analisar criticamente os difusos processos culturais que surgem no mundo transmoderno após uma compreensão sobre os processos de colonização que alocam as regiões do novo mundo, especificamente da América Latina em relação aos percursos da colonialidade e sua articulação na nova era de direitos globais, como o caso dos Direitos Humanos em meados do século XX. Para tanto, buscou-se objetivamente analisar, partindo de uma visão decolonial, esses processos violentos da colonização dentro de uma óptica do sistema-mundo rearranjada por Enrique Dussel e suas implicações dentro do espaço temporal da transmodernidade na era dos direitos universais. Diante disso, fez-se necessário as abordagens críticas das vertentes decoloniais e pós-coloniais para embasar a historicidade - ou a não-história relatada - em argumentar esses questionamentos e reflexões dos difusos processos culturais que irrompem a sociedade contemporânea. Essa pesquisa tem como metodologia de análise cunho hipotético-dedutivo e utilizou-se da técnica a coleta e revisão bibliográfica de materiais para análise focal da mesma. Ao final, demonstramos que, mesmo com os processos culturais distintos, é necessário dentro das vertentes críticas decoloniais, um apreço aos propósitos dos direitos humanos como meio de garantir um mínimo digno de referências legais aos diversos sujeitos de direito na contemporaneidade.
\end{abstract}

Palavras-Chave: Colonialidade; Direitos Humanos; Enrique Dussel; Joaquín Herrera Flores; Seyla Benhabib.

\section{Resumen}

La investigación tiene como propuesta analizar críticamente los difusos procesos culturales que surgen en el mundo transmoderno tras una comprensión sobre los procesos de colonización que asignan a las regiones del nuevo mundo, específicamente de América Latina en relación a los recorridos de la colonialidad en relación a la nueva era de derechos globales como el caso de los derechos humanos a mediados del siglo XX. Para ello, se buscó objetivamente analizar, partiendo de una visión decolonial, estos procesos violentos de la colonización dentro de una óptica del sistema-mundo reordenada por Enrique Dussel y sus implicaciones dentro del espacio temporal de la transmodernidad en la era de los derechos universales. Por eso, se hicieron necesarios los enfoques críticos de las vertientes de coloniales y postcoloniales para basar la historicidad -o la no-historia relatada- en argumentar esos cuestionamientos y reflexiones de los difusos procesos culturales que irrumpen la sociedad contemporánea. Esta investigación tiene como metodología de análisis cuño hipotético-deductivo y se

1 "O presente trabalho foi realizado com apoio da Coordenação de Aperfeiçoamento de Pessoal de Nível Superior - Brasil (CAPES) - Código de Financiamento 001”.

2 Doutoranda em Direitos Humanos; Universidade Regional do Noroeste do Estado do Rio Grande do Sul UNIJUÍ; Ijuí, Rio Grande do Sul, Brasil. gabrieli_camargo@outlook.com

${ }^{3}$ Doutoranda em Direitos Humanos; Universidade Regional do Noroeste do Estado do Rio Grande do Sul UNIJUÍ; Ijuí, Rio Grande do Sul, Brasil. b.medeirosbolzani@gmail.com 
utilizó de la técnica la recolección y revisión bibliográfica de materiales para análisis focal de la misma. Al final, demostramos que, aún con los procesos culturales distintos, es necesario dentro de las vertientes críticas decoloniales, un aprecio a los propósitos de los derechos humanos como medio de garantizar un mínimo digno de referencias legales a los diversos sujetos de derecho en la contemporaneidad.

Palabras claves: Colonialidad; Derechos Humanos; Enrique Dussel; Joaquín Herrera Flores; Seyla Benhabib.

\begin{abstract}
In order to investigate critically, the diffuse cultural processes that arose from the transmodern world before a comprehensive understanding of the processes of colonization that also saw the regions of the new world, specifically from Latin America in relation to colonialism and its articulations to new years globais, as or the case of two Human Directions in the twentieth century. For this reason, it is objectively sought to analyze, based on a decolonial vision, these violent processes of colonization within an optical system of the world-system restarted by Enrique Dussel and his implications within the temporal space of transmodernity were two universal directions. It is necessary to discuss the criticisms of decolonial and poster colony in order to base historicity - or a related story - in arguing these questions and reflections of two different cultural processes that break contemporary society. This research has been carried out as a method of analysis of the hypothetical-deductive and the technique used to collect and review the bibliography of materials for focal analysis of the work. Last year, we demonstrate that, as different cultural processes, it is necessary within two critical criticisms, that I appreciate two human purposes for the purpose of guaranteeing a minimum worthy of legal references to various subjects of a contemporary nature.
\end{abstract}

Keywords: Coloniality; Human Rights; Enrique Dussel; Joaquín Herrera Flores; Seyla Benhabib.

\title{
1 Introdução
}

Em uma composição musicada a artista chilena Ana Tijoux descreve inúmeros paradigmas que perpassam a sociedade na transmodernidade. Na composição da música Vengo (2014), Tijoux recita que busca respostas, com suas veias abertas, como um livro aberto em prontidão para apreender a história ancestral de seu povo. Após referenciar Eduardo Galeano, a artista proclama a procura coletiva pelo povo latino americano em resgatar os saberes ancestrais de suas comunidades nativas, as referências históricas não contadas sobre o conhecimento dos seus e de sua própria terra.

Por meio da arte, Tijoux prossegue em suas referências ao estimular em seus versos o ideal de descolonizar o que ensinaram e de buscar a história silenciada da nossa terra saqueada. Abordando uma nova vertente da teoria crítica, versa em seus cânticos a importância deste rompimento com a história contada e ensinada, que traz a perspectiva e a narrativa do colonizador. É estabelecido um novo olhar, fundamentalmente sobre os processos violentos da colonização, como os genocídios dos indígenas e no articulado processo que resulta na colonialidade do saber.

Refletindo ainda sobre o processo violento de colonização, Tijoux procura conhecer a própria terra, aquela que foi a "descoberta das Américas". De acordo com o pós-moderno Tzvetan Todorov (2010, p. 7) sobre este paradigma, a factual descoberta que se fez do outro - 
pelo eu europeu - perpassa um rompimento ético e violento. Para os críticos do establishment (estabelecimento homogêneo da historicidade ocidental) significou que a partir do século XVI ocorreu a perpetuação do maior genocídio da história humana. Ademais, a música de Ana Tijoux propõe uma busca pelo real e por respostas sobre esses processos de reconhecimento que rompem com o hegemônico-histórico europeu.

A musicalidade de Ana Tijoux auxilia na compreensão desses processos, da colonização à colonialidade e como essa região conhecida como o novo mundo, especificamente a América Latina, ainda responde pelos atentados oriundos desse projeto de enriquecimento europeu. Nesse contexto, este estudo busca a conversação entre esses dois conceitos, colonização e colonialidade dentro do sistema mundo, analisado por Enrique Dussel e Aníbal Quijano. Esta proposta está situada na perspectiva mais universal das mudanças no ordenamento jurídico internacional dos direitos humanos como processo cultural de Joaquín Herrera Flores, onde se estabelece a análise aqui exposta.

A partir disso este trabalho parte da seguinte indagação: é possível que os direitos humanos sejam refletidos, discutidos e ressignificados dentro de uma óptica dos estudos decoloniais? Para essa discussão, após as explanações sobre a colonização e a colonialidade, observa-se a vertente crítica do debate entre universalistas e comunitaristas, embasado por Seyla Benhabib. Para o desenvolvimento da reflexão são incorporados alguns dos principais entendimentos dos autores que pesquisam sobre o tema para referenciar essa proposta metodológica hipotético-dedutiva.

Ao seu desenvolvimento, este trabalho tem como objetivo analisar, partindo de uma visão decolonial, esses processos violentos da colonização dentro de uma óptica do sistemamundo rearranjada por Enrique Dussel e suas implicações dentro do espaço temporal da transmodernidade na era dos direitos universais. Diante disso, fez-se necessário as abordagens críticas das vertentes decoloniais e pós-coloniais para embasar a historicidade - ou a nãohistória relatada - em argumentar esses questionamentos e reflexões dos difusos processos culturais que irrompem a sociedade contemporânea.

\section{O sistema-mundo para Enrique Dussel}

Conhecido pelo seu trabalho sobre a Filosofia da Libertação, ligado à práxis da libertação do humano oprimido, o argentino Enrique Dussel nos brinda com diversas análises sobre filosofia e ética nesse período mais contemporâneo da história. A proposta do autor concentra-se em romper com a hipótese desenvolvida pela ideia de o sistema-mundo surgir apenas com o eurocentrismo. Compreende que é importante quebrar com o padrão de 
conhecimento histórico reformulado pelos europeus de que a história mundial perpassa apenas pela Europa (DUSSEL, 2002).

Dussel (2004, p. 203) cita os diversos modos de análise que os autores do período (Enciclopedistas; Hegel; Kant; Marx; Weber) desenvolveram para afirmar que, na trajetória, o Ocidente fazia parecer ter a plena realização da liberdade e da civilização, e que o continente europeu seria o destino para a história universal. A ideia que perpassa a visão sobre o sistemamundo desde o final do século XV, era de que a Europa após o descobrimento das Américas, não poderia ainda ser considerada o centro desse sistema-mundo pois regiões (América, África e Oceania) até o presente momento não tinham sido "descobertas" em suas totalidades. Portanto, é após este processo que o sistema-mundo passa a ser considerado, observado pelo início do processo da economia-mundo europeia (DUSSEL, 2004).

A partir de uma análise sobre a teoria da dependência dos países ditos do terceiromundo, como aqueles da América Latina, iniciam-se discussões acerca da centralidade europeia nesse sistema gerido há apenas cinco séculos. De acordo com Dussel (2004, p. 203, tradução nossa), "[a] modernidade tinha sido o gerenciamento (management) da dita centralidade do sistema-mundo" em que esta modernidade seria considerada a primeira Era Moderna, dos discursos hegemônicos eurocêntricos, com a ascensão do continente no sistema-mundo como resultado da descoberta e da exploração das Américas. Momento este que foi central para a organização espacial da estrutura dos Estados, das bases da origem primitiva do capitalismo e, consequentemente, da acumulação primitiva de capital. Nesse sentido, a hipótese desse sistema-mundo seria

[que] a 'ascensão do Ocidente' resultou da vantagem comparativa que a Europa moderna (especialmente durante o Renascimento) havia sido dada pelas grandes descobertas científicas, metais preciosos (prata e ouro), a nova força de trabalho incorporado ao sistema (dos índios, dos escravos africanos dos séculos XVI ao XVIII na América), novos alimentos (batata Inca, milho, tomate e chocolate mexicano etc.), os milhões de quilômetros adicionados à agricultura das colônias européias pela conquista e à invenção de novos instrumentos econômicos. Tudo isso permitiu o triunfo da Europa em concorrência com o mundo islâmico, hindustão, sudeste da Ásia ou China. Além disso, os europeus, graças à caravela, foram os únicos que conseguiram atravessar os oceanos, armar navios com canhões de alta potência e dominar primeiro o Attântico e depois o Índico e o Pacífico (DUSSEL, 2004, p. 204, tradução nossa).

Dussel $(1994 ; 2004)$ embasa sua teoria abordando nuances da história oriental no período, exemplificando com caso da China que era o centro cultural do Mundo até o século XVIII. Fundamenta a ideia de que o centro dessa sistemática inter-regional encontrava-se ao oeste dos territórios orientais chineses, no qual a região indo-americana se estabelecia fora de 
seus horizontes marítimos. Mas a China não poderia ser a base hegemônica desse novo sistema “[...] ou ao menos não obteve peso próprio no sistema-mundo, anterior ao capitalismo e a modernidade por não ter descoberto a América" (DUSSEL, 2004, p. 206, tradução nossa). Portanto, a China que era considerada um centro cultural, econômico e político até o século XVIII não poderia ser considerada moderna ou capitalista. Sobretudo, detinha seu peso desenvolvimentista próprio, com uma política considerada despótica e um modo de produção próprio da região asiática. A estruturação da hegemonia europeia se mostra possível apenas após a primeira revolução industrial.

Dussel $(1994 ; 2004)$ se utiliza das passagens abordadas por Adam Smith na "Riqueza das Nações” de 1776 (início das trocas comerciais entre Estados Soberanos), no intuito de demonstrar o quanto a região asiática era admirada pelos europeus por sua organização e capacidade econômica. A China, nesse período, se estabelecia como uma unidade muito mais desenvolvida que o continente de Adam Smith. A mudança dos padrões mercantis de fluxo de mercadorias e de pessoas passaria a se configurar dinamicamente com o descobrimento da América, onde os europeus, até então periferia dos mercados chineses, passaram a deter um poder de compra mais amplo com os novos recursos (principalmente prata e ouro) que expropriaram das terras ameríndias. Partindo dessas indicações, Dussel (2004) passa a analisar as conexões entre o antigo sistema inter-regional com o novo sistema do novo mundo, construindo, assim, o primeiro sistema-mundo. De acordo com Dussel (2004, p. 209, tradução nossa),

[a] Europa pode então comprar, graças ao dinheiro latino-americano, no mercado chinês; isto é, pode vender pouquíssimas mercadorias-produto como resultado de sua indústria, subsumindo o trabalho agredido europeu, porque é uma região produtivamente subdesenvolvida, sem concorrência possível antes do maior 'desenvolvimento' da produção de produtos chineses, como utensílios de porcelana, tecidos de seda, etc.

Essa mudança paradigmática entre o antigo e o novo sistema ${ }^{4}$ foi essencial para o fortalecimento da economia do continente europeu. A crise do sistema de produção e distribuição dos mercados chineses e indostano permitiu a ascensão do Ocidente como potência nos próximos séculos. Analisando os trabalhos de Max Weber, Dussel $(2002 ; 2004)$ compreende que a base sistêmica capitalista surgiu na Europa pelos regimes de propriedade e pelos anseios de propriedade dissipados pela ética calvinista, sendo assim, impossível de

\footnotetext{
${ }^{4}$ Para aprofundamento, ver mais em "Para descolonizar os estudos de economia política e os estudos póscoloniais: Transmodernidade, pensamento de fronteira e colonialidade global" de Ramón Grosfoguel (2008). Disponível em: https://doi.org/10.4000/rccs.697. Acesso em: 08 maio 2020.
} 
ocorrer nas regiões orientais. Observa que na ideia do individualismo - base da ética calvinista - a riqueza passava a ser considerada uma benção divina, legitimando a propriedade privada. Afirma "[que] a disciplina de uma subjetividade austera permitiram que surgisse o capitalismo, e não o corporativismo chinês ou quase o feudalismo mágico da cultura bramânica do Indostano" (DUSSEL, 2004, p. 210, tradução nossa).

Esse sistema inter-regional capitalista que demarcava a China até o século XVIII como uma potência produtora de mercadorias manufaturadas foi entrando em recesso com certos fatores internos e externos, remodelando progressivamente sua estrutura políticaeconômica. Dentre estes fatores, a mudança de dinastia Qin no século XVIII que buscava pela sua política externa uma máxima expansão territorial (conquista de Formosa), obteve vitória sobre os mongóis e uma pacificação na região do Tibete. Além disso, com a dinastia se fortalecendo, buscou-se o estabelecimento de fronteiras com o Vietnã, Myanmar e com o Nepal, entre tantas outras ações de política imperial (DUSSEL, 2004).

É exatamente neste período de instabilidade de posições políticas (relações externas e internas), da abertura dos portos aos europeus, que as crises focais ascenderam na China. Dentre os conflitos, destaca-se a primeira Guerra do Ópio em 1840 onde foi concedido o território de Hong-Kong aos britânicos em 1842, e como resultado o Tratado de Pequim de 1860 no qual fica estabelecido a abertura de 11 portos e vantagens em trocas comerciais com os europeus. Dussel $(1994 ; 2004)$ ainda aponta que pela sua extensão territorial, o mercado interno chinês era mais rentável ao Estado que o fluxo do mercado externo. Como consequência, a economia chinesa até então estável atravessaria esse período por constantes abalos frente às novas interações mercantis.

\section{0 projeto de modernidade e os excluídos}

Sobre esse projeto estruturado e nomeado como modernidade consideram-se alguns escritos do português Boaventura de Sousa Santos (2010; 2013a), para quem o pensamento moderno ocidental é um pensamento abissal. Desse modo, outros saberes que coexistem com a racionalidade hegemônica eurocêntrica ocidental têm sido tratados como um pensar abissal, marginalizados, quando não suprimidos pelos valores desse sistema de pensamento. Para Santos $(2010$, p. 32,33) essa configuração “[...] consiste num sistema de distinções visíveis e invisíveis, sendo que as invisíveis fundamentam as visíveis”.

Em uma perspectiva dialética tem-se desse lado da linha o sul global e, do outro, acima da linha, o norte global. Um passa a existir de modo preponderante sobre o outro, sobre esses outros saberes que são apagados, esquecidos, não relevantes e/ou incompreensíveis. Ao 
sul da linha "não há conhecimento real; existem crenças, opiniões, magia, idolatria, entendimentos intuitivos ou subjetivos, que, na melhor das hipóteses, podem tornar-se objetos ou matéria-prima para a inquirição científica" (SANTOS, 2013, p. 34). Essa divisão invisível, embora notória, "separa de um lado ciência, filosofia e teologia, e, do outro, conhecimentos tornados incomensuráveis e incompreensíveis", pois que não obedecem aos critérios científicos de "verdade" (SANTOS, 2010, p. 34).

Dois fatores são fundamentais para a criação dessas linhas globais modernas, o conhecimento e o direito codificado. Ao norte encontram-se os critérios científicos para a construção do saber, baseados na técnica, na objetividade e na fragmentação, afirmando possuir o monopólio de uma pretensa distinção entre o verdadeiro e o falso. De modo semelhante à essa modulação encontra-se o direito moderno, codificado e positivado a partir da linha de cima, composto pela análise dual entre legal e ilegal, únicas relevantes à lei e sua distinção passa a ser universal (SANTOS, 2013b). Nesse sentido:

\begin{abstract}
Esta dicotomia central deixa de fora todo um território social onde ela seria impensável como princípio organizador, isto é, o território sem lei, fora da lei, o território do a-legal, ou mesmo do legal e ilegal de acordo com os direitos não oficialmente reconhecidos. Assim, a linha fundamenta a dicotomia visível entre o legal e o ilegal que deste lado da linha organiza o domínio do direito (SANTOS, 2010, p. 34).
\end{abstract}

O domínio desses fatores proporcionou o controle hegemônico da estruturaçãosistêmica pela Europa até as primeiras décadas do século XX. Verifica-se desse modo que a primeira linha da modernidade muito provavelmente foi "[o] Tratado de Tordesilhas, assinado entre Portugal e Espanha (1494), mas as verdadeiras linhas abissais emergem em meados do século XVI com as amity lines (linhas de amizade)" (SANTOS, 2010, p. 35). Essa arquitetação ocorreu através do imperialismo. As constitutivas do Estado moderno (superestrutural do sistema internacional) vincularam-se aos processos de poder e de dominação para consolidação de instituições nacionais e redes globais, resultado deste mesmo processo imperial (SANTOS, 2010; 2013b). De acordo com Santos (2010, p. 36):

De meados do século XVI em diante, o debate jurídico e político entre os estados europeus a propósito do Novo Mundo concentra-se na linha global, isto é, na determinação do colonial, não na ordenação interna do colonial. Pelo contrário, o colonial é o estado de natureza onde as instituições da sociedade civil não tem lugar. Hobbes refere-se explicitamente aos 'povos selvagens em muitos lugares da América' como exemplares do estado de natureza. O colonial constituiu o grau zero a partir do qual são construídas as modernas concepções de conhecimento e direito. As teorias do contrato social dos séculos XVII e XVIII são tão importantes pelo que dizem como pelo que silenciam. 
Portanto, analisar esse período considerado uma modernidade precoce (séculos XV XVIII) passa a ser essencial no contexto aqui discutido. Como referência temporal, o "descobrimento" das Américas iniciava o primeiro processo de globalização do sistemamundo. Com a anexação do território Ameríndio pelos espanhóis permite-se nessa transição que a Europa inicie esse sistema-mundo, mesmo sendo periferia cultural e econômica do continente asiático até meados do século XVIII.

Com o avanço mercantilista o peso dos metais preciosos como padronagem das trocas comerciais se estabelece, passando a ser de extrema importância para o crescimento europeu. Em virtude da prata e do ouro saqueados das terras ameríndias, frente a falta dos metais no mercado externo indochinês, o mercado inter-regional passa a ser mantido pela compra exponencial de produtos indochineses pelos europeus. Dussel (2004, p. 213, tradução nossa) esclarece que "[...] metais preciosos integraram a Europa entre os séculos XV e XVIII, o Velho Mundo como o extremo oeste do sistema mundial nascente, sendo apenas uma região secundária em termos de produção de mercadorias".

Nesse sentido, a primeira modernidade passa a ser gerida pelos hispânicos de associação "humanista", manufatureira e mercantil. Nessa modernidade que teve duração de mais ou menos três séculos no sistema-mundo, a Europa ainda se encontrava representada como periferia ao mundo-central dos mercados indochineses. É exatamente nesse período transitório que se produziria o que se denomina como colonialidade poder ${ }^{5}$. A colonização seria assim resultado do imperativo poderio europeu frente à periferia colonial nascente nas colônias ameríndias. Paralelamente a esse período, os mercados indochineses se fechavam em um projeto nacionalista, facilitando o fortalecimento exponencial do domínio europeu nas crescentes colônias de exploração.

Com as inúmeras mudanças paradigmáticas dos padrões e fluxos dentro do sistema, a Europa - até então periferia como salienta Dussel (2002; 2004) começa a acumular forças, econômica-política e intersubjetiva - através das linhas gerais da dominação pelo poder do conhecimento e do direito nesse novo sistema-mundo ${ }^{6}$. Nesse período, o continente europeu

\footnotetext{
${ }^{5}$ Conforme explica Grosfoguel (2008, p. 126), “[...] colonialidade do poder' designa um processo fundamental de estruturação do sistema-mundo moderno/colonial, que articula os lugares periféricos da divisão internacional do trabalho com a hierarquia étnico-racial global e com a inscrição de migrantes do Terceiro Mundo na hierarquia étnico-racial das cidades metropolitanas globais. Os Estados-nação periféricos e os povos nãoeuropeus vivem hoje sob o regime da "colonialidade global" imposto pelos Estados Unidos, através do Fundo Monetário Internacional (FMI), do Banco Mundial (BM), do Pentágono e da OTAN. As zonas periféricas mantêm-se numa situação colonial, ainda que já não estejam sujeitas a uma administração colonial”.

6 “A incorporação de tão diversas e heterogêneas histórias culturais a um único mundo dominado pela Europa, significou para esse mundo uma configuração cultural, intelectual, em suma intersubjetiva, equivalente à
} 
passava por mudanças geopolíticas intensas, de crises e guerras, estabelecimento de fronteiras dos novos Estados Nacionais e se ressentia com o despovoamento gerado por doenças e pestes. A saída frente a tais obstáculos foi a descoberta das Américas e a abertura de novos mercados produtivos, provenientes da revolução ideológica-científica que abria a visão para um mundo maior que aquele inter-regional (DUSSEL, 2004).

Sistematicamente os territórios e os povos ameríndios passam a sofrer a primeira onda colonizadora da primeira modernidade, sendo gravemente onerados pelo impacto da iniciada onda globalizadora através da conquista de suas terras, corpos e imaginários. Nesse processo violento de dominação, os ameríndios nativos passam a conviver com “[...] o racismo, o mito da superioridade europeia, a exploração econômica, a dominação política, a imposição da cultura externa, produzindo a síndrome da colonialidade do poder" (DUSSEL, 2004, p. 214, tradução nossa).

Esse processo de dominação ocorre fundamentalmente dentro dos territórios e corpos colonizados, resultando no "[...] exercício assimétrico da autoridade ensejado pelo controle de recursos materiais e simbólicos, compelindo aqueles que estão submetidos a comportamentos que beneficiam os que detêm poder" (MIGUEL, 2018, p. 15). Dessa forma, através da dominação pelos europeus, que historicamente se mostrou de forma extremamente violenta, as riquezas materiais e imateriais passam a ser extraídas para enriquecimento das capitanias mercantis a fim de manter as monarquias europeias, portuguesas e espanholas, que passavam por crises constantes nesse período. Eduardo Galeano reflete:

\begin{abstract}
Havia de tudo entre os indígenas da América: astrônomos e canibais, engenheiros e selvagens da Idade da Pedra. Mas nenhuma das culturas nativas conhecia o ferro e o arado, o vidro e a pólvora, e tampouco empregava a roda. A civilização que se abateu sobre essas terras, vindas do outro lado do mar, vivia a explosão criadora do Renascimento: a América surgia como uma invenção a mais, incorporada junto com a pólvora, a imprensa, o papel e a bússola ao agitado nascimento da Idade Moderna (GALEANO, 2013, p. 35).
\end{abstract}

Desse modo, os europeus apropriados dos recursos ameríndios passam a deter dentro do mercado - global - poder econômico para transferir riquezas de uma região à outra sem nem ao menos ter um produto próprio, apenas seus serviços de transportes para transferência de recursos. Já aos mercados indochineses que também passavam por crises, muito em conta

articulação de todas as formas de controle do trabalho em torno do capital, para estabelecer o capitalismo mundial. Com efeito, todas as experiências, históricas, recursos e produtos culturais terminaram também articulados numa só ordem cultural global em torno da hegemonia européia ou ocidental. Em outras palavras, como parte do novo padrão de poder mundial, a Europa também concentrou sob sua hegemonia o controle de todas as formas de controle da subjetividade, da cultura, e em especial do conhecimento, da produção do conhecimento" (QUIJANO, 2005, p. 121). 
do aumento significativo do fluxo de comércio externo, buscavam proteger seus mercados, valiosos por serem requeridos pelas metrópoles mercantis europeias.

Estava demarcado a primeira fase da modernidade. Com o fim da primeira era, a segunda resultava do desdobrar da Revolução Industrial que alcançaria significativamente o Reino Unido no século XVIII. A Revolução Industrial seria o símbolo de um sistema que crescia. O problema agrário alcançava as nações européias, nesse período a terra era a maior fonte de riqueza, refletido pelos teóricos fisiocratas no período. Como salienta Hobsbawm:

\begin{abstract}
E o ponto crucial do problema agrário era a relação entre os que cultivavam a terra e os que e os que a possuíam, os que produziam sua riqueza e os que a acumulavam. Do ponto de vista das relações de propriedade agrária [...] o lavrador típico era o índio que trabalhava à força ou se encontrava virtualmente escravizado, ou o negro que trabalhava como escravo; um pouco mais raramente, um camponês arrendatário, um meeiro ou algo semelhante. [...] A economia característica da zona de plantação escrava, cujo centro ficava nas ilhas do Caribe, ao longo do litoral da América do Sul e no litoral sul dos EUA, era a produção de algumas culturas de exportação de vital importância: açúcar, em menos quantidade o café e o tabaco, tintas e, a partir da revolução industrial, sobretudo o algodão (HOBSBAWM, 2016, p. 36-37).
\end{abstract}

Em conjunto com a Revolução Industrial, a reforma político-ideológico da Revolução Francesa demarcava esta nova estrutura de poder. Estruturava-se uma nova fase dos símbolos históricos embasados nas mudanças transcorridas no seio do continente europeu. Através dos dispositivos de dominação, esses ideais (acumulação, direitos individuais, economia nacional) espalharam-se ao mundo como parte processual para o tão alcançado renome de potência mundial. É também neste período que se inicia a ascensão do Ocidente frente à decadência oriental no sistema-mundo.

As mudanças estruturais que permeariam a nova configuração do mundo com a ascensão eurocêntrica no sistema-mundo passam economicamente por uma produção crescente no continente que se preparava para alcançar esse crescimento desde o século XV. Essa expansão dos mercados, com todas as possibilidades de intercâmbio de produtos, passava estrategicamente pelos fluxos europeus, o que deu base ao desenvolvimento produtivo da Europa no século XIX. Em conjunto com as mudanças paradigmáticas das estruturações políticas que alcançariam o continente após a Revolução Industrial e com os ideais individuais da Revolução Francesa, o continente promulgava uma segunda onda de colonização.

A segunda onda de colonização era territorialmente estruturada no continente Africano. Historicamente vislumbre pelas manifestações imperialistas das nações pelo Congresso de Berlim em 1885, resulta em um desmembramento territorial para domínio e 
exploração de terras e de força de trabalho escrava. Como bem reflete Dussel (2004, p. 217, tradução nossa), os continentes Latino e Africano, "com sua população indígena e afro, também foram relegados como um mundo colonial distante, periférico às semiperiferia e à Espanha e Portugal pré-industrial”. A base do capitalismo mundial era elencado com o domínio colonial. A partir desse período - do desenvolvimento econômico industrial, dos ideais político-ideológico liberalistas, das técnicas científicas e do novo modelo de organização social estrutural dos Estados, se constituiu a segunda era moderna. Para Dussel (2004, p. 217, tradução nossa),

[...] O eurocentrismo brilhará sem oposição e dominará o mundo colonial com a face da cultura ocidental ocidental, como a expressão' de sempre 'do centro mais desenvolvido da humanidade. Isso justificará o processo de expansão "civilizadora" européia (Inglaterra transformada em missão de civilização no mundo, expressou Hegel triunfantemente) para esconder, excluir e ignorar como "povos sem história" pela "cultura ocidental".

Nesse processo de colonização, que reflete a colonialidade do poder nas regiões que sofreram com essa problemática histórica de exclusão, acabou sendo acoplado o ideal do moderno. Esse ideal sustenta uma classificação na qual tudo que está fora ou que ficou para trás não mais serve para o crescimento "civilizatório" da humanidade como sociedade diante da universalidade eurocêntrica. No entanto, Dussel (2004, p. 218, tradução nossa) adverte que desde o começo do século XIX isso têm surtido efeito eficaz nas culturas não-européias, "[...] as elites neocoloniais se ocuparam de aplaudir essa ideologia eurocêntrica sem um oponente crítico até muito recentemente".

Consequentemente, a exclusão dos sujeitos não-europeus passa a ser central no ideal de civilização no período secundário da modernidade, perpassando pela dominação cultural e ideológica, além da econômica e política pelos hegemons (potências hegemônicas) do sistema. Assim, tanto o velho como o novo mundo passam nesses séculos a suportar (mesmo com muita luta e resistência) essas mudanças estruturais vindas do norte, que transformaria o mundo em uma grande periferia que os atende - primordialmente - até meados do século XX. Esse paradigma irá se transformar com as mudanças estruturais do sistema internacional a partir das duas grandes guerras que resultaram na bipolaridade global.

\section{Divergências entre a pós-modernidade e a transmodernidade}

Para discutir um pouco sobre esses questionamentos temporais, além do autor base deste artigo, Enrique Dussel, consideram-se as reflexões de Stuart Hall, pesquisador jamaicano radicado no Reino Unido, que discutirá em planos abertos a ideia das 
configurações dessa crise da modernidade que caracteriza o mundo do século XX. Em seu livro "A identidade cultural na pós-modernidade”, Stuart Hall buscará entender a complexidade das múltiplas identidades que tomam o sujeito nessa temporalidade pósmoderna. Onde observa uma mudança transformadora na sociedade que “[...] está fragmentando as paisagens culturais de classe, gênero, sexualidade, etnia, raça e nacionalidade, que, no passado, nos tinham fornecidas sólidas localizações” (HALL, 2015, p. 10).

No cerne das transformações, as crises de identidade são relacionais com as mudanças estruturais do mundo, principalmente em relação à pessoa humana que passa a ser o indivíduo central de análise. Isso portanto é causa-consequência do protagonismo do indivíduo que ganha ainda mais centralidade com a proteção internacional do estabelecimento dos Direitos Humanos (1948) após a ascensão dos regimes totalitários na eurásia e com as terríveis violências praticadas pelos Estados na II Grande Guerra (1939-1945). Nesse sentido, compreender esse período é essencial para priorizar o objeto de pesquisa: é exatamente nessa crise da modernidade, das crises de identidades subjetivas dos sujeitos nesse período, que se refletem as mudanças estruturais e institucionais que surgiram em meados do século XX. Assim, "um outro aspecto desta questão da identidade está relacionada ao caráter da mudança na modernidade tardia; em particular, ao processo de mudança conhecida como globalização e seu impacto sobre a identidade cultural" (HALL, 2015, p. 12).

As sociedades modernas doutrinadas pelo modelo civilizatório eurocêntrico passam a ser as sociedades das mudanças rápidas e constantes, transformando o tempo e o espaço, desalojando especialmente o sistema social tradicional. Esse desalojamento estrutural perpassa um deslocamento ${ }^{7}$ dos centros de poder, no qual se rompe com o ideal articulado e organizador único, antecessor ao proposto pela modernidade europeia. Outrossim, "as sociedades da modernidade tardia [...] são caracterizadas pela diferença” (HALL, 2015, p.14). De acordo com o autor,

[ainda] era possível, no século XVIII, imaginar os grandes processos da vida moderna como estando centrados no indivíduo sujeito da razão. Mas à medida que as sociedades modernas se tornavam mais complexas elas adquiriam uma forma mais coletiva e social. As teorias clássicas liberais de governo, baseadas nos direitos e consentimento individuais, foram obrigados a dar conta das estruturas do Estadonação e das grandes massas que fazem uma democracia moderna, As leis clássicas

\footnotetext{
${ }^{7}$ Stuart Hall argumenta sobre as ideias propostas de Ernesto Laclau: “[...] o deslocamento tem características positivas. Ele desarticula as identidades estáveis do passado, mas também abre possibilidade de novas articulações - a criação de novas identidades, a produção de novos sujeitos e os que ele chama de 'recomposição da estrutura em torno de pontos nodais particulares de articulação" (HALL, 2015, p. 14).
} 
da economia política, da propriedade, do contrato e da troca tinham de atuar, depois da industrialização, entre as grandes formações de classe do capitalismo moderno. [...] o cidadão individual tornou-se enredado nas maquinarias burocráticas e administrativas do Estado moderno (HALL, 2015, p. 20).

Nesse processo moderno no qual as nacionalidades são as principais fontes de identidades culturais, o que passa a deslocar tão incisivamente essas identidades no fim do século XX é "[...] um complexo de processos e forças de mudança, que, por conveniência, pode ser sintetizado sob o termo "globalização" (HALL, 2015, p. 39). E são sobre esses efeitos globais, destes processos em escala mundial que despontam os teóricos que elencam esse período de pós-modernismo. Passa-se a analisar principalmente os fluxos culturais “"...] entre as nações, e o consumismo global criam possibilidades de identidades partilhadas como consumidores para os mesmos bens, clientes para os mesmos serviços, públicos para as mesmas mensagens e imagens" (HALL, 2015, p. 42). Dentre os exemplos e referências sobre os pós-modernos podemos citar Frederic Jameson, Zygmunt Bauman, Gilles Deleuze, Gilles Lipovetsky e Ulrich Beck.

Contrapondo-se a essa estrutura discursiva, Enrique Dussel, através da titularidade de Gianni Vattimo, conduz um novo olhar sobre esse ideal temporal através do signo epistemológico da transmodernidade. Isto é, uma afirmação da multiculturalidade excluída pela modernidade europeia, como referência em seu texto. $\mathrm{O}$ autor caracteriza esse fenômeno pós-moderno como um contínuo fluxo da modernidade como dominação, principalmente do poder-saber. Compreende que a crítica da modernidade deve perpassar pela questão do eurocentrismo, “[...] de certo modo se pensa que a sociedade pós-convencional, urbana e pósindustrial, do mercado cultural livremente escolhido, será instalada universalmente e, com ela, a mesma pós-modernidade global” (DUSSEL, 2004, p. 219, tradução nossa).

Dussel ainda elenca em sua crítica que esse pensar pós-moderno reitera esse ideal homogeneizante da razão moderna e universalista, já tão contestada. Observa criticamente que o pensar pós-moderno não tem consciência suficiente das culturas excluídas pela colonização no início da modernidade. De maneira clara explica que

\footnotetext{
8 “A globalização implica um movimento de distanciamento da idéia sociológica clássica da 'sociedade' como um sistema bem delimitado e sua substituição por uma perspectiva que se concentra na forma como a vida social está ordenada ao longo do tempo e espaço. [...] A globalização caminha em paralelo com um reforçamento das identidades locais, embora isso ainda esteja dentro da lógica da compressão espaço-tempo; a globalização é um processo desigual e tem sua própria 'geometria de poder'; e a globalização retém alguns aspectos da dominação global ocidental, mas as identidades culturais estão, em toda arte, sendo relativizadas pelo impacto da compressão espaço-tempo" (HALL, 2015, p. 39-48).
} 
O cargo de pós-modernidade não tira o eurocentrismo; supõe-se óbvio que a humanidade futura alcançará as mesmas características de uma "situação cultural" que a Europa pós-moderna ou os Estados Unidos, na medida em que eles são "modernizados" pelo processo de globalização já iniciado, irreversível e inevitável. Sob o signo dessa 'inevitabilidade' modernizadora, o pós-modernismo é profundamente eurocêntrico, pois não pode imaginar que as culturas excluídas em sua valiosa positividade pelo processo colonial moderno (desde 1942) e iluminadas (desde 1789) puseram o poder em uma data: a da hegemonia industrial da Europa no sistema mundial devido ao desaparecimento da China e do Hindustão pré-industrial e não pré-moderno) pode independentemente, 'modernizar' e desenvolver criativamente suas próprias culturas universais em um estágio próximo e após o final, no final, à extinção da modernidade europeia-norte-americana com a reivindicação de uma universalidade "única", além de seu limite, além de seu "último momento", além de sua atual crise, além do momento pós-moderno de modernidade (DUSSEL, 2004, p. 219-220, tradução nossa).

Essa perspectiva crítico-reflexiva denominada por Dussel (2006) de "transmodernidade" passa a ser um processo que se origina e passa a se movimentar de outro lugar, distinto do lugar centralizado pela Europa e Estados Unidos. Essa transmodernidade passa a ser protagonista de uma expressão das inúmeras culturas que foram excluídas do processo moderno. Sobreviventes da homogeneização cultural e de epistemicídios, essas culturas, muitas mais antigas que o próprio projeto moderno, andaram paralelamente com o ideal desse projeto. Mas adquiriram potência e força própria na multiculturalidade do ser e do saber, onde é possível "[...] uma pluralidade cultural futura após o fim da modernidade e do capitalismo: as culturas vivas e férteis, diferentes e criativas" e que não sejam "simplesmente uma cultura pós-moderna, pois esse é apenas um último estágio da modernidade” (DUSSEL, 2004, p. 221, tradução nossa).

Para Enrique Dussel (2004), esse mais além que o transmoderno traz em sua essência a busca dos diversos sujeitos excluídos pelo processo civilizatório da modernidade ocidental, na qual as culturas excluídas - grande parte da humanidade - guardam imenso potencial e qualidade criativa para o futuro da humanidade. É nessa disputa de sentidos para o futuro da humanidade que se sobressaem os saberes dos povos nativos, que detém dentro de suas comunidades uma relação única com a natureza, de sustentabilidade. Dussel (2004) ainda esclarece com lucidez que em relação ao futuro que se encurta numa atualidade prolongada, seriam essas multiculturas que deveriam assumir desde a transmodernidade, com códigos para um futuro mais ecológico, com valores ancestrais, de riqueza humana não-valorativa, mais plural e decolonial, tolerante e democrático, que os códigos e fatores dos propósitos modernos. 


\section{Colonização como processo, colonialismo como resultado}

Um dos principais aportes do poderio eurocêntrico na modernidade consiste na metáfora criada sobre o estado de natureza de John Locke, como aponta Seyla Benhabib (2006). Considera a autora de maneira crítica, em relação ao Segundo Tratado sobre o Governo, “[...] como um argumento da filosofia moral e uma intervenção complexa na justificação de um regime de colonização de propriedades que ainda estava em desenvolvimento" (BENHABIB, 2006, p. 86, tradução nossa). A colonização gerou processos de violência em diversos pontos territoriais, como na América Latina (comunidades, povos e etnias), marcando na subjetividade a introjeção do individualismo, independência, autodeterminação e autonomia desses novos sujeitos atomizados. Com esmero, Franz Fanon ${ }^{9}$ disserta sobre essa relação complexa dos novos sujeitos:

Para assimilar a cultura do opressor e aventurar-se nela, o colonizado teve de oferecer garantias. Entre outras, teve de fazer as suas as formas de pensamento da burguesia colonial. Isso verifica-se na inaptidão do intelectual colonizado para dialogar. Não sabe se tornar-se inessencial perante objeto ou a ideia. Pelo contrário, quando milita no seio do povo, vai de surpresa em surpresa. Fica literalmente desarmado com a boa fé e com a honestidade do povo. O risco permanente que o espreita consiste em fazer populismo. Ele transforma-se numa espécie de sabichão que responde a cada frase do povo, transformando as respostas em sentença. Ora o felá, o desempregado, o esfomeado, não aspira à verdade. Ele não diz que é a verdade, porque ele é a verdade no seu próprio ser” (FANON, 1982, p. 23).

O longo processo da colonização da então denominada América Latina (XV - XX) guarda resquícios do pensamento elitista colonial-europeu. Esses resquícios são o que Aníbal Quijano (2005) descreve como colonialidade. Dessa necessidade de se fortalecer interculturalmente identidades latinoamericanas, pensadores críticos de diversas vertentes têm se apoiado em buscar a não-história contada. Como refletido na música de Ana Tijoux em "Vengo", se busca a história dos povos ameríndios segunda suas próprias narrativas e seus próprios sentidos. Conhecido também como colonialismo a colonização como processo de dominação e a colonialidade como

\footnotetext{
9 "Fanon é o provedor da verdade transgressiva e transicional. Ele pode ansiar pela transformação total do Homem e da Sociedade, mas dá la de modo mais eficaz a partir dos interstícios incertos da mudança histórica: da área da ambivalência entre raça e sexualidade, do bojo de uma contradição insolúvel entre cultura e classe, do mais fundo da batalha entre representação psíquica e realidade social. Sua voz é ouvida de forma mais clara na virada subversiva de um termo familiar, no silêncio de uma ruptura repentina: O negro não é. Nem tampouco o branco. A incômoda divisão que quebra sua sensação de mudança. Aquele alinhamento familiar de sujeitos coloniais - Negro/Branco, Eu/Outro - é perturbado por meio de uma breve pausa e as bases tradicionais da identidade racial são dispersadas" (BHABHA, 2005, p. 70).
} 
[...] uma estrutura de dominação/exploração onde o controle da autoridade política, dos recursos de produção e do trabalho de uma população determinada domina a outra de diferente identidade e cujas sedes centrais estão, além disso, localizadas noutra jurisdição territorial [...] O colonialismo é, obviamente, mais antigo, enquanto a Colonialidade tem vindo a provar, nos últimos 500 anos, ser mais profunda e duradoura que o colonialismo (QUIJANO, 2010, p. 84).

A colonialidade passa a ser um fator que constituirá o padrão sistêmico capitalista, está calcada na "imposição de uma classificação racial/étnica da população do mundo como pedra angular do referido padrão de poder e opera em casa um dos planos, meios e dimensões, materiais e subjetivos, da existência quotidiana e da escala societal” (QUIJANO, 2010, p. 84). Esse processo passa a ser explanado dentro do sistema-mundo através da constituição e colonização da América Latina, no qual paralelamente emerge o projeto moderno e capitalista. Nesse sentido, se estabelecem eixos centrais nesse novo padrão de dominação exploratório, o qual se baseia através do saber, do poder e da economia.

Essas mudanças protagonizam a centralidade homogênea europeia como eixo específico do novo padrão de poder, configurando, assim, novas identidades societais da colonialidade dentro dessa geocultura estruturante de relação entre o velho e o novo mundo. Onerosamente, "as relações intersubjetivas correspondentes, nas quais se foram fundindo as experiências do colonialismo e da colonialidade com as necessidades do capitalismo, foramse configurando como um novo universo de relações intersubjetivas de dominação" (QUIJANO, 2010, p. 85). Essas novas relações intersubjetivas de poder, sob dominação europeia, preconiza essa realidade por toda modernidade na América Latina e nos territórios que ainda respondem pela formação colonial de seus corpos e espaços. Para Quijano:

[...] desse universo intersubjetivo, foi elaborado e formalizado um modo de produzir conhecimento que dava conta das necessidades cognitivas do capitalismo: a medição, a externalização (ou objetificação) do cognoscível em relação ao conhecedor, para o controle das relações dos indivíduos com a natureza e entre aquelas em relação a esta, em especial a propriedade dos recursos de produção" (QUIJANO 2010, p. 85).

Sobre a apropriação dos recursos de produção, Seyla Benhabib (2006) propõe uma releitura sobre o argumento moral-filosófico do teórico clássico John Locke, o qual, já abordado, classifica os espaços e sujeitos a serem colonizados pela justificativa do regime de propriedade do colonizador. Benhabib (2006, p. 86), recordando a passagem sobre a metáfora do estado de natureza, esclarece que esta "é uma metáfora que combina, de maneira impressionante, o histórico com o psicológico, o analítico com o cultural" no qual essa condição natural não estaria legislada sobre leis comuns. Esses ameríndios - dos lugares 
incomuns, como cita Locke - vivam sob formas de organização social questionáveis aos padrões legais do homem moderno europeu, sob a selvageria, mas que Bartolomé de Las Casas testemunha o contrário em seu memorial de 1552.

A metáfora orquestrada sob o estado de natureza, nesse sentido, não passa de uma afirmação histórica desse individualismo, autonomia e independência que o europeu colonizador carregava em si. Esse ideal remonta a concepção que nenhuma lei civil poderia guiar aqueles detentores da racionalidade moderna e liberal - que encarava aqueles "outros ameríndios" como não-proprietários. Esses outros - mesmo pertencente de suas terras comunitárias - não possuiriam sua própria legitimidade sobre o território "sem lei', que foi dominado pelo individualismo patrimonial e proprietário do sujeito europeu. Esse pensamento, de acordo com Seyla Benhabib (2006) viria a legitimar e justificar a colonização da América.

A expropriação dos ameríndios não foi apenas um feito histórico na visão de Locke, mas consagrou um ato moral, um dever de domesticação e civilização dos selvagens. Por outro lado, a colonização passava a acelerar esse processo moderno de desenvolvimento do governo de consenso - entre os europeus - e do regime de propriedade privada nas terras colonizadas, sendo o genocídio ameríndio justificado como um sacrifício necessário ao desenvolvimento civilizatório perante a visão do colonizador (BENHABIB, 2006). Nesse sentido, com a violentas relações de dominação foram se naturalizando as experiências por aqueles dominados, alterando as relações históricas da colonialidade em conjunto com a geocultura do poderio sistêmico do capitalismo, que era inaugurado com um modo de produção do conhecimento que foi em seu cerne, etnocêntrico. Assim, "denominado racional, foi imposto e admitido no conjunto do mundo capitalista como a única racionalidade válida e como emblema da modernidade" (QUIJANO, 2010, p. 86).

Mesmo com as revoluções históricas ocorrendo, das mudanças específicas de conjuntos - como a inserção da política-ideológica liberal da democracia - e de revoltas de resistência colonial, os eixos estruturais mantiveram-se sustentados na relação de dominação. Por um longo período esse poderio se manteve quase impenetrável, resultado do casamento entre capitalismo e colonialismo no mundo moderno. E, finalmente, a partir da virada do século XX entra em crise. O eurocentrismo passa a retratar ainda uma das facetas educadoras da hegemonia cultural moderna dentro do sistema, "trata-se da perspectiva cognitiva durante o longo tempo do conjunto do mundo eurocentrado do capitalismo colonial/moderno e que naturaliza a experiência dos indivíduos nesse padrão de poder” (QUIJANO, 2010, p. 86). 
Em meados do século XIX com o processo de mundialização do capitalismo e do seu poder, o sistema começa a entrar em crise devido às mudanças estruturais que decorriam da modernização de territórios, muitos deles, ex-colônias europeias. Desse modo, "O lugar do capitalismo mundial foi ocupado pelo Estado-nação e pelas relações entres Estados-nação, não só como unidade de análise mas como único enfoque válido do conhecimento sobre o capitalismo" (QUIJANO, 2010 p. 87). Surgem, gradualmente, as teorias críticas ao sistemamundo, muitas delas vislumbrando essa relação desproporcional entre Estados e a relação com a sociedade. Como exemplos pode-se mencionar as análises ideológicas-econômicas liberais e as críticas advindas do pensamento socialista utópico, além do materialismohistórico proposta por Marx e Engels. Considera-se que "a revolta intelectual contra essa perspectiva é contra esse modo eurocentrista de produzir conhecimento nunca esteve exatamente ausente particularmente na América Latina" (QUIJANO, 2010, p. 87).

É importante recordar que no decorrer do século XX, principalmente com o fim da Segunda Guerra Mundial, se iniciam os estudos críticos sobre a sistemática capitalista e de dependência histórica, como as teorias desenvolvimentista ${ }^{10}$. Esses estudos foram os embriões da CELAC na América do Latina, que nesse período, passava a tratar desse poderio do capital no campo das relações sociais que constituíam as dinâmicas do poder em território latino. Assim, inaugura-se esses debates latinoamericanos sobre uma nova totalidade histórico-social do seu passado para seu presente, com uma racionalidade não-hegemônica e não-eurocêntrica, propondo um equilíbrio sobre seu desenvolvimento próprio e autônomo nesse capitalismo cada vez mais global.

\section{Direitos Humanos como processo cultural}

Conforme a perspectiva histórica apresentada segundo a categoria conceitual sistemamundo, desde um enfoque latino americano, considera-se que a colonialidade é resultado de um longo processo histórico de violência e dominação. Desse modo, as teorias críticas das vertentes decoloniais e pós-coloniais inauguram as reflexões de algumas das problemáticas que vêm de encontro com o desenvolvimento societal do mundo. Sendo assim, "[dessas] situações históricas sistêmicas de dominação (patriarcalismo, colonialismo/imperialismo e

\footnotetext{
${ }^{10}$ Da América Latina, sem dúvida a mais influente das tentativas de mostrar de novo a mundialidade do capitalismo, foi a proposta de Raul Prebisch, e dos seus associados, de pensar o capitalismo como um sistema mundial diferenciado em 'centro' e 'periferia'. Foi retomada e reelaborada na obra de Immanuel Wallerstein, cuja proposta teórica do 'moderno sistema-mundo', de uma perspectiva onde confluem a visão marxista do capitalismo como um sistema mundial e a braudeliana sobre a longa duração histórica, reabriu e renovou o modo decisivo o debate sobre a reconstrução de uma perspectiva global, na pesquisa científico-social do último quartel do século XX (QUIJANO, 2010, p. 87).
} 
capitalismo), invariavelmente inconscientes para a maioria esmagadora dos seres humanos, resultam, por exemplo, as reações e respostas" (SANTOS; LUCAS, 2015, p. 43). A artista e compositora Ana Tijoux pede por respostas e por um movimento latino americano de descolonização dos nossos corpos e dos territórios.

Neste diálogo de encontros e respostas estão os negros e negras, os povos nativos e da Floresta, mulheres, os campesinos, imigrantes, a comunidade LGBTQIA+ (Lésbicas, Gays, Bissexuais, Trans, Queer, Interssexo, Assexual, +). Em busca de respostas e de dignidade estão todos os marginalizados pelo sistema que muitas vezes corrobora com as exclusões social, cultural e econômica desses sujeitos. Buscam antes de tudo espaço e dignidade humana nessa transmodernidade e capitalismo voraz. Nesse sentido, é evocada como proposta a ideia de Joaquín Herrera Flores (2009) que considera os direitos humanos como processo cultural e, assim, potencialmente direcionado para a proteção daqueles excluídos, como referência ética e jurídica de proteção para essas reivindicações plurais.

Com as transformações das relações sociais nesse período transmoderno, tal como embasada na origem cultural dos direitos humanos, vislumbra-se uma tentativa de reconhecer essa pluralidade através da proteção desses direitos, principalmente quando referenciamos as a Declaração Universal do Direitos Humanos em 1948. Entre cartas e declarações, inúmeras reconheceram a pluralidade das normatividades, o que incentivou a construção de normas basilares para constituintes mais plurais de Estados na virada do século XXI, tais como a o Constitucionalismo plurinacional e intercultural na Bolívia e Equador.

Nesse sentido, na esteira de Herrera Flores (2009) observam-se os direitos humanos como produtos culturais, resultados dessas mudanças históricas que se dão no âmbito internacional na era global, efeito desses processos mais reativos dos sujeitos e em relação à proteção da oikos (casa comum) que habitam. Herrera Flores (2009) defendendo sua hipótese passa a flertar com o relativismo quando aborda a ideia de que a universalidade dos direitos humanos tende a culturalmente fechar-se sobre si. Isto é, situa e apreende o outro como o incivilizado, o bárbaro, o colonizado, o subdesenvolvido.

Versando sobre a desconstrução do conceito de Direitos Humanos como valores universais, a partir de discursos filosóficos consistentes, Herrera Flores (2009) aborda que nessa construção esses direitos são em sua base produto cultural, enclausurados desde o século XV ao XXI pela modernidade ocidental capitalista. Em algumas circunstâncias os Direitos Humanos como jurisdição emplacaram mudanças em novos sistemas de relações na sociedade, como instrumento direcionado para as mobilizações sociais reivindicativas diante de violação dos Direitos Humanos. 
Deve-se observar os Direitos Humanos enquanto Declaração (1948) normativa e como um importante instrumento no combate aos processos colonizadores. Portanto, essa instrumentalidade dos Direitos Humanos faz frente combativa à violação dos direitos humanos resultantes da ordem sistema-mundo capitalista que onera o alcance de dignidade humana aos grupos historicamente excluídos, fundamental no sentido proposto neste trabalho. Assim, os Direitos Humanos como processos culturais são sobretudo instrumentos jurídicos de garantias fundamentais. Herrera Flores (2009) passa a abordá-los como produto cultural da humanidade, algo que sustente relações sociopolíticas, econômicas, jurídicas, sistemas que se legitimam em si mesmos em diversos retratos e formações sociais, construídas historicamente. Nesse sentido, Herrera Flores (2009, s. p.) sustenta os Direitos Humanos como um caminho para a dignidade e afirma que

A partir desse princípio de dignidade, consideramos os direitos humanos como produtos culturais, quer dizer, como convenções surgidas como reação diante dos entornos de relação que o capital veio impondo desde o século XVI até a atualidade. Também, e como consequência do caráter cultural dos direitos, temos insistido na importância de relacioná-los com seus contextos, ou seja, com a forma de produção de riqueza (e pobreza), com os processos de divisão sexual, étnica e territorial do fazer humano e, por último, com as formas organizativas, funcionais ou antagonistas aos dois elementos anteriores, E, ao final, concluímos num conceito que podemos resumir na seguinte frase: os direitos humanos são o conjunto de processos de luta pela dignidade humana.

Dessa forma, os Direitos Humanos devem ser entendidos como um mínimo ético para início de discussões, principalmente quando embasada a culturalidade, seja ela singular ou comunitária. A dignidade humana neste caso deve ser o suporte para as relações valorativas ora na sistemática capitalista, ora fora dessa codificação. A dignidade humana, portanto, deve ser entendida como substrato para a construção de espaços e organizações mais simétricas e funcionais àqueles que, em sua luta proclama a efetivação de direitos.

\section{Os Direitos Humanos e a era globalizante}

Quando nos apoiamos sobre os saberes de Herrera Flores (2009) para discutir os Direitos Humanos, é essencial entender que estes são, em seu imperativo basilar, um mínimo ético para o diálogo intercultural (LUCAS, 2013). Assim sendo, os Direitos Humanos como processo cultural na era da globalização, da hipervelocidade de fluxos (corpos, bens e informação), passam a questionar essa ideia de produção de identidades culturais. Neste processo dialético e dinâmico em relação ao sujeito dentro da sociedade, este particularmente reproduz e reflete as condições de existência para o específico do seu eu-coletivo; esse eu é 
atravessado pela necessidade de diferenciação para com as outras culturas (LUCAS, 2013). Por conseguinte, esse fenômeno chamado globalização acaba trazendo para os diversos sujeitos - indivíduos e coletivos, um espectro da explosão cultural de novos padrões que incide no Estado-nação Moderno.

Essa faceta multicultural, presente nos Estados Nacionais, assume uma postura globalizante nesse período do último quarto do século XX. A cultura como um processo pode ser conceituada como o "conjunto de saberes, representações, símbolos, costumes e formas de vida compartilhados (comunitariamente) por uma coletividade de indivíduos [...] reproduzindo uma concepção particular de sociabilidade" (LUCAS, 2013, p. 166). Outrossim, essa concepção sobre o conceito de cultura se dá de forma "holística, orgânica, sensível, autotélica, e recordável" como bem discorre Norbert Elias (1994). Em vista disso, a cultura como signos passa a ser a diversidade de incontáveis formas de ser, de viver, de se organizar socialmente, não comporta uma narrativa unívoca e universal proclamada pela homogeneidade cultural moderna.

Com o estabelecimento dos fatores da globalização, os sujeitos sociais passam a não ter mais fixação apenas em um lugar (ambiente) ou local (espacial), sejam elas por necessidade ou por opção, os indivíduos na contemporaneidade constituem suas vidas em variados ambientes. Parafraseando Ulrich Beck, “[...] é um processo de conexão entre culturas, pessoas e locais que tem modificado o cotidiano dos indivíduos" (LUCAS, 2013 p. 168). No entanto ocorre dentro desse período transmoderno uma mundialização cultural, uma reprodução de uma cultura que está em todos sujeitos e em todos os lugares, capaz de reproduzir hábitos, conceitos e simbologias, reflexo fundante de uma redução material e simbólica do Estado-nação na transmodernidade. De acordo com Lucas:

\footnotetext{
Nessa circunstância de entrecruzamento entre o local e o mundial, os Estados-nação sofrem uma redução em seu papel de protagonistas na conformação das identidades individuais, uma vez que, para além dos tradicionais vínculos do cidadão nacional como o território e a nação, multiplicam-se os referenciais identitários que amparam o surgimento de forças locais em busca de reconhecimento para as suas demandas particulares, atreladas não mais à ideia primordial da nacionalidade, mas as reivindicações de cunho cultural, político, de gênero, entre outras ${ }^{11}$ (LUCAS, 2013, p. 169).
}

\footnotetext{
11 “A modernidade objetiva das nações aos olhos do historiador versus antiguidade subjetiva aos olhos dos nacionalistas. A universalidade formal da nacionalidade como conceito sociocultural - no mundo moderno, todos podem, devem e hão de "ter" uma nacionalidade, assim como "têm" este ou aquele sexo - versus a particularidade irremediável das suas manifestações concretas, de modo que a nacionalidade "grega" é, por definição, sui generis. O poder "político" dos nacionalismos versus a sua pobreza e até sua incoerência filosófica. Em outras palavras, o nacionalismo, ao contrário dos outros "ismos", nunca gerou grandes pensadores próprios: nenhum Hobbes, Tocqueville, Marx ou Weber. Esse "vazio" cria certa condescência entre os
} 
Entre os reclames de protagonismos identitários e de diferenças com os efeitos globalizantes que não se universalizam, mas comprimem, promove-se o retorno à ideia de comunidade e às formas de pertença para com os seus similares culturais. Com os processos acentuados de mudanças rápidas e estabilidade provisória, a subjetividade do sujeito se torna flexível na medida em que os sujeitos se deparam com a multiplicidade de significações e representações no âmbito cultural. Onde identificar-se com algo temporariamente, ou, o nãofixo, se torna possível nesse todo fluído. Com essas identidades fixas e tradicionais enfraquecidas, como o caso das identidades nacionais, tanto pelos interesses da globalização ou da financeirização econômica que se interpenetram, se restabelece um novo paradigma identitário, onde "[...] novas identidades surjam, outras se fortalecem, algumas enfraquecem e outras se hibridizam" (LUCAS, 2013, p. 172).

Dessas fragilidades identitárias tradicionais, os sujeitos de identidades fragmentadas/flexíveis retornam às comunidades como abrigo mediante as incertezas globais, onde as identidades comunitárias voltam a ser um apoio frente às inseguranças "[...] como uma tentativa de se estabelecer lealdades entre semelhantes em uma sociedade de sujeitos desenraizados" (LUCAS, 2013, p. 172). Nesse sentindo, esse retorno às comunidades identitárias tem acirrado os conflitos do "nós contra eles', alimentando cada vez mais o fechamento cultural de certos grupos. Porém, esse fechamento cultural pode significar incerteza já que prejudica os diálogos interculturais dentro dessa sociedade heterogênea da contemporaneidade.

Nessa sociedade contemporânea, onde tudo se apresenta fugaz e efêmero e as identidades apreendidas como 'naturais', tais como Estado, família, religião, raça e gênero tornam-se frágeis frente às novas concepções de realidades líquidas, é "[...] quando a identidade perde as balizas sociais que a faziam parecer um fenômeno natural, o sentimento de pertença a algum lugar ou determinada cultura torna-se ainda mais importante" (LUCAS, 2013, p. 174). Principalmente para aqueles que buscam a vinculação do "nós" - o Estado passa a proporcionar espaços de transição no meio global para definirem-se a sociabilidade cultural.

Dessa nova concepção de espaço que surge na contemporaneidade, onde as coisas passam a ocorrer em tempo real (inclusive virtualmente), a ideia de desterritorialização das

intelectuais cosmopolitas e poliglotas [...] O 'nacionalismo' é a patologia da história e do desenvolvimento moderno, tão inevitável quanto a 'neurose' no indivíduo, e que guarda muito da mesma ambiguidade de essência, da tendência interna de cair na loucura, enraizada nos dilemas do desamparo imposto à maior parte do mundo (o equivalente do infantilismo para as sociedades), sendo em larga medida incurável" (ANDERSON, 2008, p. 31). 
realidades culturais produz o divórcio do sujeito com seu contexto imediato. O que resulta nessa dialética entre o global e o local que são visíveis nos novos mapas de formas identitárias. Isso é marcado essencialmente pelo fechamento cultural em forma de fundamentalismos e nacionalismos em diversos territórios da sociedade, que buscam, sobretudo, a afirmação das identidades locais frente a uniformização patrocinada pela globalização (LUCAS, 2014). Desse modo "[as] identidades culturais periféricas começam a influenciar e até mesmo modificar o imaginário social global pela defesa de suas diferenças perante a homogeneização" (LUCAS, 2013, p. 178). Se estrutura assim a codificação da exclusão-inclusão. Essas reflexões sobre a afirmação das identidades, nesse período onde a cultura se estabelece no centro dos debates, ocorrem dentro de diversas áreas das ciências humanas e sociais.

Com o fim do período denominado mundialmente como Guerra Fria intensificaram-se os conflitos, como nos contextos de imigração, direitos humanos e democracia. O mundo se projeta e se torna cada vez mais multipolar e multicultural e a discussão sobre os contextos de diversidade cultural são panos de fundo de agendas internacionais. Por isso, o debate entre comunitaristas e universalistas torna-se imprescindível. As demandas multiculturais que postulam proteção e tratamento especial em relação às suas particularidades, onde reproduzem suas identidades comunitárias, baseiam-se na ideia do particularismo cultural. E passam a ser em sua base a defesa dos comunitaristas ou relativistas culturais frente a universalização cultural que impera na homogeneização da globalização através da universalidade cultural.

Em seu livro As reivindicações da cultura: Igualdade e diversidade na era global, Seyla Benhabib (2006) reflete criticamente sobre as generalizações feitas pelo Ocidente, resquício do imperativo modernizador que alavanca o hemisfério norte desde o século XVIII. Nessa totalização que se homogeneiza perpassam identidades, uniformidade de processos e desenvolvimento de coesão de sistemas de valores. Seyla Benhabib (2006) constrói sua crítica sobre o universalismo do ser ocidental, o qual já pressupõe a homogeneidade de outras culturas - nós e eles - uma ideia binária de sociedade bipolarizada.

Seyla Benhabib (2006), com o intuito de superar essa bipolarização, se baseia no pensar de Tzvetan Todorov para abordar a dialética dos nós e do outro, a qual surge também entre o relativismo cultural e o universalismo. Defende a busca por um ideal de reconhecimento da hibridação radical e poli-qualidades de todas as culturas - que em si mesmas, nem a cultura nem as sociedades são holísticas, mas sim sistemas de ação. Ações políticas de reivindicação do direito de auto-expressão cultural, baseado no direito de 
cidadania, ambos universalmente reconhecidos (BENHABIB, 2006, p. 60). Nesse sentido, ela busca nos clássicos contratualistas a ideia sobre a natureza humana, ou essência humana que em alguma tese poderia nos definir enquanto espécie, além de nossa capacidade de formação de princípios morais de capacidade universal.

Essa universalidade que Benhabib (2006) reflete ganha potência a partir dos ideais kantianos e das ideias da objetividade filosófica sobre o conteúdo normativo da razão humana, da validade procedimental de investigação. A autora questiona as ideias de imparcialidade e de objetividade, de verificação intersubjetiva de resultados e informação do conteúdo normativo. Nesse sentido, compreende que todos os humanos devem ser considerados como iguais mortais ${ }^{12}$, ou seja, devem ser tratados com igual direito ao respeito moral. Assim é que “[o] universalismo pode ter um sentido jurídico” (BENHABIB, 2006 p. 63, tradução nossa), pois vislumbra-se principalmente nos imperativos de certos direitos básicos - os Direitos Humanos (direito à dignidade, à vida, à liberdade, à segurança, liberdade de associação e expressão).

Assim, o debate pela universalidade dos Direitos Humanos - e pelos imperativos serem individuais, estes fatores passam a ser reféns da crítica aos relativistas culturais ou comunitaristas. Ao se valer da relativização do marco de referência ética e moral dessa universalidade dos Direitos Humanos, os comunitaristas se referem principalmente à problemática desses direitos universais romperem com a ideia de comunidade, principalmente quando ligados à linguagem, cosmovisões epistêmicas e tradições não-etnocêntricas. Benhabib (2006) tece uma crítica ao relativismo argumentando que há um perigo moral e conceitual na insistência apressada sobre a comensurabilidade total, a qual implica na dimensão epistêmica e moral, pois compreender o outro - cultural, referenda não apenas um ato cognitivo, mas é uma ação política.

Portanto o problema mensurado pelo relativismo cultural passa a ser a incomensurabilidade, e mesmo discordando do relativismo absoluto Seyla (2006) credita aos teóricos comunitários algumas ressalvas, pois são notórias certas convergências culturais na humanidade. Os sistemas de crenças e de valores, além dos modos de representação, passam a obter grande significado no mundo moderno com a ascensão das múltiplas identidades. A

\footnotetext{
12 "Eu o associaria ao princípio de que todos os seres humanos, independentemente de raça, gênero, preferência sexual, ambiente étnico, cultural, linguístico e religioso, devem ser considerados iguais a Morales e, portanto, devem ser tratados como se Morales tinha o mesmo e, portanto, deveria ser tratado como se tivesse igual direito ao respeito moral "(BENHABIB, 2006, p. 63, tradução nossa).
} 
autora ainda corresponde em sete pontos a necessidade do diálogo entre universalistas e comunitaristas pelas ações práticas:

\begin{abstract}
A interpretação das culturas como totalidades herméticas, fechadas e internamente alto coerentes é insustentável (reflete uma sociologia reducionista do conhecimento); 2. Visão que as culturas auto coerentes é refutado pelo argumento filosófico relativos a impossibilidade da incomensurabilidade e intraduzibilidade radicais; 3 . Nos convertemos em contemporâneos morais, interdependente e nossas ações também tem consequências - essa situação global cria uma nova comunidade interdependente - do nós e eles; 4. Imperativo paradigmático para entender uns aos outros e entrar em um diálogo cultural nos enfrentamentos reais entre culturas, línguas e nações; 5. Desse imperativo paradigmático surge consequências morais: através dos diálogos em que todos são participantes - humanidade - pela condição de interdependência que vivemos hoje, de intercâmbio, influência e interação em nível mundial; 6 . Todo entendimento requer regras normativas - em reconhecer o direito da participação igualitária entre todos os sócios do debate, podem ser chamadas de 'respeito universal' e 'reciprocidade igualitária'; 7. O respeito universal' e 'reciprocidade igualitária' são guias de ação. São pautas para instituições, constituem princípios normativos para guiar juízos e deliberações em situações complexas (BENHABIB, 2006, p. 77-78, tradução nossa).
\end{abstract}

Ademais, Seyla Benhabib (2006) vincula em sua abordagem a necessidade dessa universalidade dos Direitos Humanos, principalmente quando fundamentada no respeito universal e na proteção da dignidade humana como limites às ações entres os Estados e dentro de seus territórios, no contexto da sociedade contemporânea. Essa perspectiva que surge como guia para as agendas institucionais de cunho internacional e das normativas internas de cada Estado deve guiar os juízos e as deliberações em situações complexas. Exemplos disso não raras vezes envolvem os corpos femininos, como o caso histórico nigeriano quando a mutilação genital feminina é proibida - um caso crítico dos Direitos Humanos. Esse é um exemplo no qual rompe-se via institucionalização com uma prática cultural que afetava negativamente a dignidade daquelas nigerianas que se opunham à mutilação. Outros temas complexos envolvem o debate e a ponderação nessas questões, com conteúdo para uma pesquisa específica cujo objetivo não é o deste trabalho.

Em ações das práticas políticas exemplificadas acima, o embate nasce pela evidência do conflito entre a multiculturalidade e os direitos universais. Os Direitos Humanos como normativa transversal devem, nestes casos complexos, buscar garantias para a proteção da dignidade dos violentados, sendo essencial considerar também as peculiaridades de cada cultura, conforme cada situação. Portanto, quando instrumentalizados esse rol de direitos universais há a tendência de resistência e há complexidades singulares muito sensíveis. Nessa contemporaneidade cosmopolita o debate entre universalistas e comunitaristas tende a crescer exponencialmente, principalmente pela ascensão do multiculturalismo concomitante ao 
nacionalismo. Com o aumento dos fluxos globais e o fechamento de comunidades como reflexo, o debate a nível institucional requer dos sujeitos o testemunho, marcando a retomada dos debates culturais nessa sociedade ricamente plural e diversificada.

\section{Conclusões}

Relativamente os processos culturais estão passando por mudanças acentuadas devido a mudança paradigmática do espectro tempo-espaço que perpassa frente aos imperativos globalizantes das últimas décadas. A transmodernidade produz, sobretudo, mudanças de cunho socioeconômico, cultural e político nos diversos espaços territoriais do globo. Considerar a história silenciada dos povos latinoamericanos e refletir junto aos pensadores críticos da vertente decolonial são ações imprescindíveis para a discussão sobre Direitos humanos afora o centro hegemônico do mundo euro-estadunidense. Assim, buscando responder à questão hipotética desse trabalho científico se seria possível que os Direitos Humanos fossem passíveis de discussão dentro de uma óptica dos estudos decoloniais, concluiu-se como válida. Seguimos às explicações.

A busca de respostas, questionada por Ana Tijoux vem sendo cada vez mais abordada pelos pensadores decoloniais, onde os Direitos Humanos passam a abarcar esses processos culturais transversais, cada vez mais acentuados pela velocidade do hipercapitalismo. Buscar compreender esses processos culturais nos quais os direitos humanos se inserem contribui para a aceitação de outras racionalidades, de outros saberes e para a formação de novas epistemologias. Os debates entre os relativistas culturais e os universalistas ajudam a compreender a complexidade que o sistema da sociedade internacional enfrenta na transmodernidade, seja das inúmeras assimetrias de poder, seja das diferenças culturais que constituem essas sociedades. Os Direitos Humanos como processos culturais pertencem ao movimento constante do esforço pela criação e inserção do sentido contra-hegemônico destes direitos, isto é, que não reproduza a colonialidade do ser, do saber e do poder.

Os Direitos Humanos, nesse sentido, significam uma guinada importante, uma conquista da sociedade para si, resultando e demarcando uma luta contínua de busca por dignidade dos diversos povos e comunidades no globo. São estes que carecem de atenção das intuições, sejam elas internacionais ou nacionais para positivação e resguardo de direitos básicos (individuais e coletivos) na busca de uma sociedade mais igualitária, multicultural e pluriversal. Como Ana Tijoux (2014, s./p) proclama, “[...] venimos con el mundo y venimos con su canto / a construirán sueño / el brillo de la vida que habita del hombre nuevo / vengo busca un ideal de un mundo sin clase que se puede levantar". 


\section{Referências}

AUDARD, Catherine. Cidadania e Democracia Deliberativa. Porto Alegre: EDIPUCRS, 2006.

BAUMAN, Zygmunt. Modernidade Líquida. Rio de Janeiro: Zahar, 2001.

BENHABIB, Seyla. Las reivindicaciones de la cultura: igualdad y diversidad en la era global. Buenos Aires: Katz, 2006.

BHABHA, Homi K. O local da cultura. Belo Horizonte: Editora UFMG, 1998.

BRAGATO, Fernanda Frizzo; FERNANDES, Karina Macedo. Da Colonialidade do poder à descolonialidade como horizonte de afirmação dos Direitos Humanos no âmbito do constitucionalismo latino-americano. In: RCJ-Revista Culturas Jurídicas, v. 2, n. 4, 2015.

COUTO, Joaquim Miguel. O pensamento desenvolvimentista de Raúl Prebisch. Scielo, Economia e Sociedade, Campinas, v. 16, n. 1 (29), p. 45-64, abr. 2007. Disponível em: <http://www.scielo.br/pdf/ecos/v16n1/a03v16n1.pdf> Acesso em: 11 maio 2020.

DUSSEL, Enrique. 1492: El encubrimiento del Otro: Hacia el origen del "mito de la modernidad". La Paz, Bolivia: Plural Editores, 1994.

DUSSEL, Enrique. Ética de La Liberación en la edad de la globalización y de la exclusión. Madrid: Editorial Trotta, 2002.

DUSSEL, Enrique. Sistema mundo y transmodernidad. In: DUBE, Saurabh; ISHITA, Banarjee; MIGNOLO, Walter. Modernidades coloniales. México: El Colegio de México, 2004.

DUSSEL, Enrique. Transmodernidad e interculturalidad. In: DUSSEL, Enrique. Filosofía de la cultura y la liberación. México: UNAM, 2006.

DUSSEL, Enrique. Transmodernidade e interculturalidade: interpretação a partir da filosofia da libertação. Revista Sociedade e Estado, v. 31, n. 1, jan./abr. 2016. Disponível em: <http://www.scielo.br/pdf/se/v31n1/0102-6992-se-31-01-00051.pdf>. Acesso em: 09 jul 2018 .

ELIAS, Norbert. A sociedade dos Indivíduos; organizado por Michael Schroter. Rio de Janeiro: Zahar, 1994.

FANON, Franz. Os Condenados da Terra. Rio de Janeiro: Civilização Brasileira, 1968.

FLORES, Joaquín Herrera. Teoria Crítica dos Direitos Humanos: os direitos humanos como produtos culturais. Rio de Janeiro: Editora Lumen, 2009.

GALEANO, Eduardo. As Veias abertas da América Latina. Porto Alegre: L\&PM Editores, 2010.

GROSFOGUEL, Ramón. Para descolonizar os estudos de economia política e os estudos póscoloniais: transmodernidade, pensamento de fronteira e colonialidade global. Revista Crítica de Ciências Sociais, n. 80, p. 115-147, 2008. 
HALL, Stuart. A identidade cultural na pós-modernidade. Rio de Janeiro: Lamparina, 2015.

HOBSBAWM, Eric J. A era das Revoluções, 1789-1948. São Paulo: Paz e Terra, 2016.

LACLAU, Ernesto. A razão populista. São Paulo: Três Estrelas, 2013.

LIPOVETSKY, Gilles; SERROY, Jean. A cultura mundo: resposta a uma sociedade desorientada; tradução Maria Lúcia Machado. São Paulo: Companhia das Letras, 2011.

LUCAS, Doglas Cesar. Direitos Humanos e Interculturalidade: um diálogo entre a igualdade a diferença. Ijuí: Ed. Unijuí, 2013.

MIGUEL, Luis Felipe. Dominação e Resistência: desafios para uma política emancipatória. São Paulo: Boitempo, 2018.

MIGNOLO, Walter. Capitalismo y geopolítica del conocimiento: el eurocentrismo y la filosofía de la liberación en el debate intelectual contemporáneo. Ediciones del Signo, 2001.

QUIJANO, Aníbal. Colonialidad y modernidad/racionalidad. Perú Indígena, Vol. 13, No 29, 1992.

QUIJANO, Aníbal. Colonialidad del poder, eurocentrismo y América Latina. In: Edgardo Lander (Comp.); La colonialidad del saber: eurocentrismo y ciencias sociales. Buenos Aires, CLACSO, Consejo Latinoamericano de Ciencias Sociales, 2005. Disponível em:

$<$ http://biblioteca.clacso.edu.ar/clacso/sur-sur/20100624103322/12_Quijano.pdf >. Acesso em: 11 de maio de 2020.

QUIJANO, Aníbal. Colonialidad del poder y clasificación social. In: Cuestiones y horizontes: de la dependencia histórico-estructural a la colonialidad/descolonialidad del poder. Buenos Aires: CLACSO, 2014.

SANTOS, André Leonardo Copetti; LUCAS, Doglas Cesar. A (in)diferença no Direito. Porto Alegre: Livraria do Advogado, 2015.

SANTOS, Boaventura de Sousa; MENESES, Maria Paula. Epistemologias do Sul. São Paulo: Cortez, 2010.

SANTOS, Boaventura de Sousa. Pela mão de Alice: o social e o político na pós-modernidade. São Paulo: Cortez, 2013a.

SANTOS, Boaventura de Sousa. Direitos Humanos, Democracia e desenvolvimento. São Paulo: Cortez, 2013b.

SMITH, Adam. A riqueza das nações investigação sobre sua natureza e suas causas. São Paulo: Abril Cultural, 1983.

TIJOUX, Anita. Vengo. Letras, [S.1.], 2014. Disponível em: < https://www.letras.mus.br/anatijoux/vengo/traducao.html>. Acesso em: 08 ago. 2018.

TODOROV, Tzvetan. A conquista da América: a questão do outro. São Paulo: WMF Martins Fontes, 2010. 